Biochem. Lett., Vol. 5, PP. 56-69 (2009)

\title{
DIRECT EFFECT OF TESTOSTERONE ON ISOLATED CORONARY STRIPS
}

\author{
M. M. Al-Zendah and A. Al-Faqeh \\ Physiology \& Biochemistry Departements - Faculty \\ of Medicine, Al-Fateh University for Medical Sciences
}

\begin{abstract}
ABSRACT
Background: Although estrogens have been to be vasoactive hormones, the vascular effects of testosterone are not well defined. Also, administration of testosterone to men with angina has been shown to reduce myocardial ischemia. The mechanism of this effect is not clear but could be via an influence on coronary artery tone.

Objectives: We therefore planned this study to examine the vascular effects of testosterone invitro on the coronary artery strips and the potential mechanisms of its action.

Material \& methods: Strips of coronary artery were obtained from Adult male Newzea land white rabbits and mounted in Krebs solution in $50 \mathrm{ml}$ organ chambers at 37 oC. These strips are exposed to $\mathrm{PGF}_{2 a}$ as a vasoconstrictive substance then testosterone is added alone and these experiments are repeated in strips preincubated with different agents.

Results: Testosterone induces a significant relaxation of rabbit coronary artery strips precontracted by $P G F_{2 \alpha}$. Incubation of coronary strips with $N$-nitro-L-arginine methyl ester (L-NAME) inhibits partially the relaxing effect of $T$. However, incubation of these strips with indomethacin did not affect the relaxing effect of T. Moreover, incubation with barium chloride, the relaxing response of $T$ was significantly attenuated.
\end{abstract}


Al-Zendah, M. M. \& Al-Faqeh, A.

Conclusion: In conclusion, testosterone causes vasodilatation in coronary artery and the mechanism of this response involved the release of nitric oxide from endothelium and the stimulation of voltage dependent $K$ channels is responsible, at least in part, for the testosterone-induced relaxation of rabbit coronary arteries. This effect may be one of the explanations as to why testosterone has previously been shown to demonstrate beneficial effects on anginal symptoms.

\section{INTRODUCTION}

It has been proposed that gonadal steroids influence cardiovascular physiology and/or patho-physiology. Specifically, it has been proposed estrogen may protect against the development of cardiovascular diseases; however the administration of exogenous estrogen in men actually increase the risk of death from coronary artery disease ${ }^{(\mathbf{1})}$. The relationship between the level of testosterone and the incidence of coronary heart disease is still controversial in the view of the results of clinical and epidemiologic studies For example; plasma testosterone levels are reported to correlate either positively or negatively with the incidence of coronary artery disease in men ${ }^{(2 \& 3)}$. In fact testosterone is associated with higher levels of high-density lipoprotein in men and was correlated negatively with risk factors such as fibrinogen ,plasminogen activator inhibitor-1 and insulin ${ }^{(4)}$, suggesting that hypotestosteronemia may be a risk factor for coronary atherosclerotic heart disease in men. In addition, plasma androgen levels are higher in normotensive males than in their hypertensive counterparts ${ }^{(5)}$.

The fact that post-menopausal women have a lower incidence of coronary heart disease and myocardial infarction than men of a similar age has led to the hypothesis that testosterone may predispose to coronary artery disease. However, there has been no direct evidence linking testosterone administration to an increases incidence of coronary heart disease and myocardial infarction (6\&7). 
The direct effect of testosterone on the coronary artery and any underlying mechanisms of action are not well known. So, the purpose of this study was to assess the effect of testosterone on isolated rabbit coronary arteries and the potential mechanisms of its actions.

\section{MATERIAL \& METHODS}

Adult male New zealand white rabbits (weight $2-3 \mathrm{~kg}$ ) were used in this study. Animals were sacrificed by decapitation then a rapid thoracotomy was performed and the heart was rapidly excised by cutting the great vessels and placed in oxygenated Krebs-Henseleit buffer solution.

Coronary arteries were dissected, cleaned from loosely adherent connective tissue and blood then dropped in ice cold KrebsHenseleit buffer solution [composed of (mol/L) NaCL 118.3, KCl 4.7, $\mathrm{CaCl} 2$ 2.5, MgSO4 1.2, K2PO4 1.2 and glucose 11.1 and containing $\mathrm{Na}+$ EDTA $0.026 \mu \mathrm{M}$ and adjusted to $\mathrm{pH}$ 7.4) which had previously been gassed with $95 \% \mathrm{O} 2$ and $5 \% \mathrm{CO} 2^{(8)}$. Strips of studied vessels were prepared and mounted in Krebs solution in 50 $\mathrm{ml}$ organ chambers at $37 \mathrm{oC}$. Strips were allowed to equilibrate for at least 60 minutes before experiments were begun. Isotonic contractions were recorded by an isotonic lever on the drum of a universal kymograph.

The coronary strips are exposed to testosterone (dissolved in ethanol $10 \mu \mathrm{mol} / \mathrm{L}) 7$ minutes after the addition of constrictor agent PGF $2 \alpha$ in a submaximal dose $(3 \mu \mathrm{mol} / \mathrm{L})$. Then the coronary strips are exposed to other experiments to determine the possible mechanism of testosterone action: (a) in which N-nitro-L-arginine methyl ester (L-NAME) is an inhibitor of endothelium-derived relaxing factor (EDRF) synthesis from L-arginine in vascular endothelial cells in a dose of $(100 \mu \mathrm{mol} / \mathrm{L})$ was added to coronary arterial strips with endothelium 20 minutes before being contracted with PGF2 $\alpha$ and then testosterone is added. (b) in which 
Al-Zendah, M. M. \& Al-Faqeh, A.

indomethacin ,an inhibitor of prostanoid synthesis was dissolved in an $\mathrm{NaCO} 3$ solution $(10 \mu \mathrm{mol} / \mathrm{L})$ was incubated with strips with endothelium for 20 minutes before being precontracted with PGF $2 \alpha(3 \mu \mathrm{mol} / \mathrm{L})$ then testosterone is added. (c) To determine the possible involvement of cGMP in the testosterone effect, these strips are incubated with Methylene blue $(10 \mu \mathrm{mol} / \mathrm{L})$ for $20 \mathrm{~min}$. before being contracted with PGF $2 \alpha(3 \mu \mathrm{mol} / \mathrm{L})$. Testosterone $(10$ $\mu \mathrm{mol} / \mathrm{L}$ ) was subsequently added. (d) in which barium chloride, a nonspecific inhibitor of potassium channels ${ }^{(14)}$ in $(3 \mathrm{mmol} / \mathrm{L})$ was added to coronary artery strips 20 minutes before being contracted with PGF $2 \alpha(3 \mu \mathrm{mol} / \mathrm{L})$.

Testosterone, L-NAME, indomethacin, Methylene blue, barium chloride and PGF2 $\alpha$, all supplied by Sigma. All drugs were prepared on the day of experiment.

\section{Data analysis}

All data are presented as mean $\pm \mathrm{SD}$. Relaxations expressed as percentage relaxation of maximum contraction induced by $\mathrm{PGF}_{2 \alpha}$ $(3 \mu \mathrm{mol} / \mathrm{L})$. The results were analyzed with a Student's test. A probability level of less than 0.5 was considered significant.

\section{RESULTS}

1-Testosterone $(10 \mu \mathrm{mol} / \mathrm{L})$ causes relaxation of coronary artery strips precontracted by PGF2 $\alpha(3 \mu \mathrm{mol} / \mathrm{L})$.

2-Praddition of L-NAME in a dose of $(100 \mu \mathrm{mol} / \mathrm{L})$ to the coronary strips significantly attenuated the relaxing response of testosterone.

3 -However, addition of indomethacin in a dose of $(10 \mu \mathrm{mol} / \mathrm{L})$ to these strips did not inhibit relaxation induced by testosterone.

4- Pre-addition of methylene blue in a dose $(10 \mu \mathrm{mol} / \mathrm{L})$ to the coronary strips had no effect on relaxation induced by testosterone $(10 \mu \mathrm{mol} / \mathrm{L})$. 
5-However, addition of barium chloride in a dose of $(3 \mathrm{mmol} / \mathrm{L})$ to these strips significantly attenuated the relaxing response of testosterone in its two doses $10 \mu \mathrm{mol} / \mathrm{L}$ ).

Table (1): Comparison between percentage relaxation of precontracted coronary strips after addition of testosterone in a dose of $(10 \mu \mathrm{mol} / \mathrm{L})$ alone, after L-NAME, after indomethacin, after MB, then after barium chloride.

\begin{tabular}{|c|c|c|c|c|c|}
\hline & 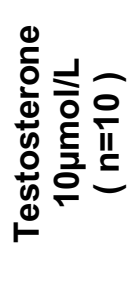 & 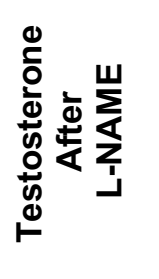 & 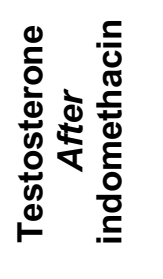 & 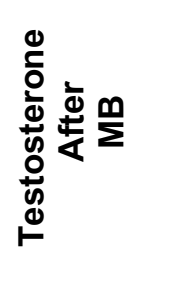 & 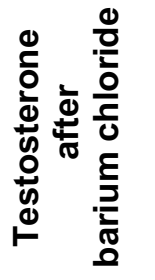 \\
\hline$\overline{\mathrm{X}}$ & 59.4 & 48.9 & 58.0 & 58.3 & 35.8 \\
\hline $\mathrm{S} \pm \mathrm{D}$ & 5.46 & 6.3 & 9.9 & 7.81 & 7.2 \\
\hline $\mathrm{P}$ & & $<0.001$ & $>0.05$ & $>0.05$ & $<0.01$ \\
\hline
\end{tabular}



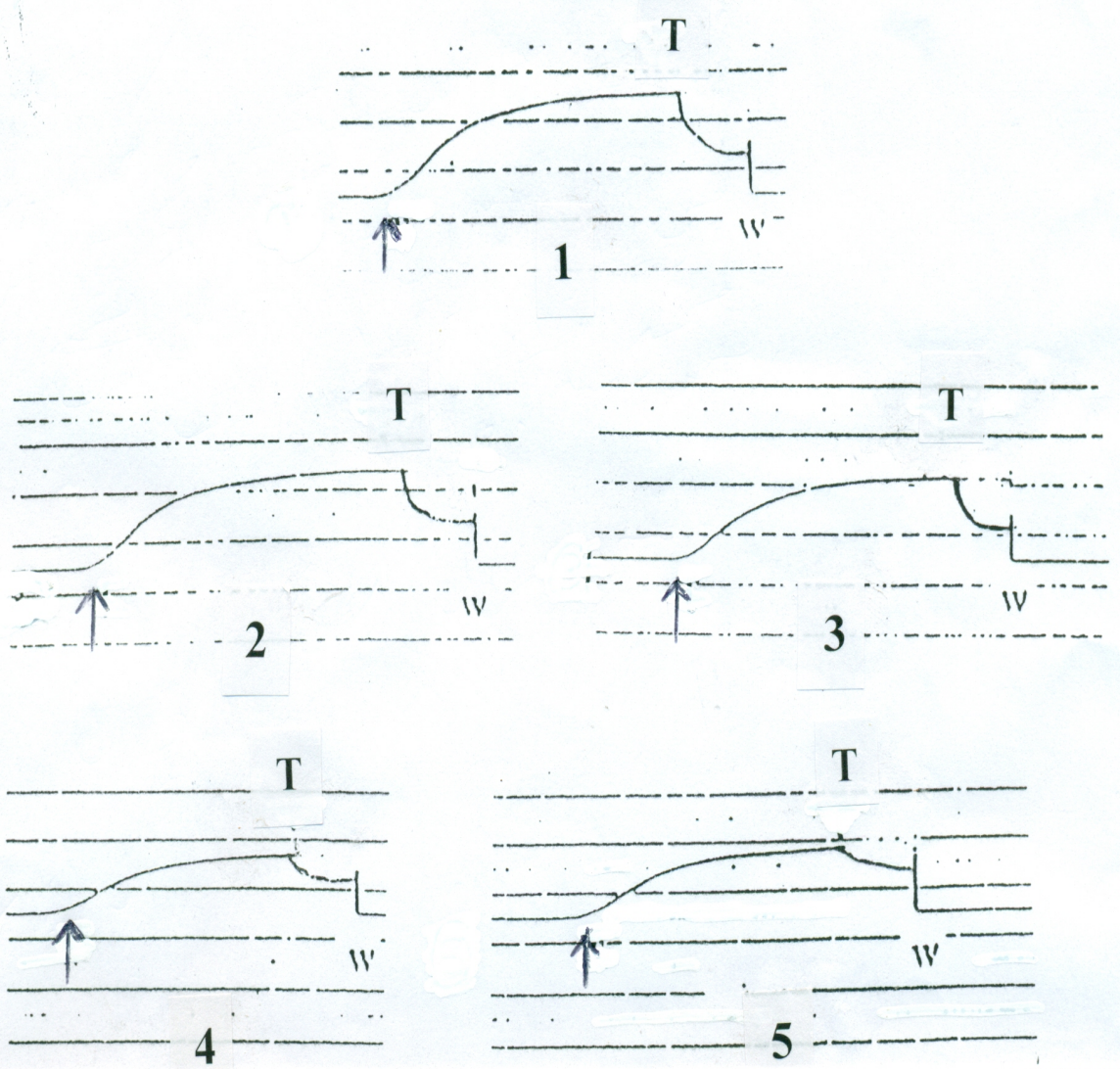

Figure (2) : Show the percentage relaxation of precontracted coronary strips afte addition of (1) testosterone in a dose of $(10 \mu \mathrm{mol} / \mathrm{L})$ alone, (2) after L-NAME, (3) after indomethacin , (4) after MB, (5) then after barium chloride 


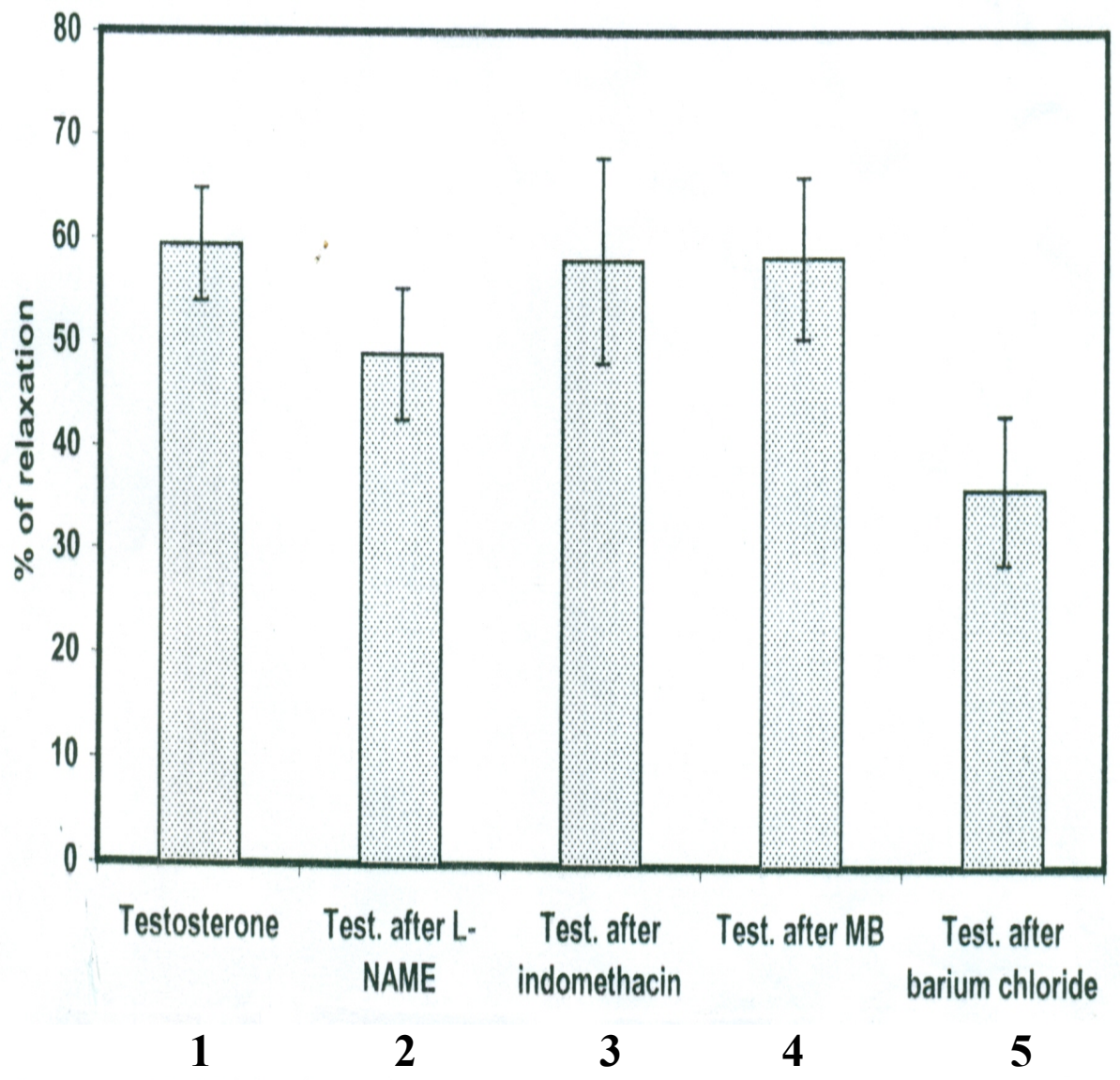

Figure (2) : Show the percentage relaxation of precontracted coronary strips afte addition of (1) testosterone in a dose of $(10 \mu \mathrm{mol} / \mathrm{L})$ alone, (2) after L-NAME, (3) after indomethacin , (4) after MB, (5) then after barium chloride 


\section{DISCUSSION}

The present study demonstrated that testosterone (10umol/L) induces relaxation in precontracted rabbit coronary arteries and this relaxation is partially through nitric oxide release as L-NAME affects this relaxation, and partially by non-specific $\mathrm{K}+$-channel opening as barium $\mathrm{Cl}$ - attenuate the relaxing response to testosterone.

These results are in agreement with previous studies which demonstrated that testosterone relaxes rabbit coronary arteries or aorta ${ }^{(8)}$ and rat thoracic aorta ${ }^{(9)}$ in vitro and canine coronary arteries in vivo ${ }^{(10)}$. Also, Ponikowska et al., (11) stated that men with type II diabetes mellitus (DM) are prone to develop androgen deficiency and these deficiencies are related to high CV mortality.

One of the commonly cited theoretical mechanisms of the beneficial effect of testosterone on anginal symptoms in these studies was coronary vasodilatation (12, 13, and 14). Testosterone treatment for several weeks' reduced objective evidence of exercise induced myocardial ischemia in patients with angina pectoris ${ }^{(15)}$. Also, there is recent study showing that testosterone level is lower in patients with ischemic heart diseases, and testosterone treatment alleviates the symptoms ${ }^{(\mathbf{1 6})}$.

However, previous studies have shown controversial results about the role of androgens in coronary artery disease (CAD). Fallah et al., ${ }^{(17)}$ reported a nonlinear association of tT levels with CAD: lower levels have a preventive effect on CAD, whereas higher values increase the risk of CAD. Also van Staa, Sprafka (18) stated that there are concerns that exogenous testosterone therapy may be associated with adverse cardiovascular effects.

Results of various studies suggest that testosterone receptors have been identified in blood vessels of human and other mammals and have been localized in the plasmalemma, cytosol, and nuclear compartments of various vascular cells, including the endothelium and the smooth muscle ${ }^{(19) .}$ 
Testosterone's endothelium-dependent effects are likely mediated at least in part through nitric oxide elaboration (20), whereas mechanisms of endothelium-independent effects involve one or more types of smooth muscle ion conductance channels ${ }^{(21)}$.

Testosterone relaxed arterial tone partly by enhancing NO release from the endothelium ${ }^{(9,10)}$ and in rabbit aorta and porcine coronary artery; testosterone induced endothelium-independent relaxation (22).

Indomethacin inhibits the synthesis of prostaglandins (23) and inhibits the transient relaxation induced by arachidonic acid in rabbit coronary arteries ${ }^{(24)}$. However, in this study, indomethacin did not affect testosterone-induced relaxation in endothelium-intact coronary arteries. These results indicate that the release of vasodilator prostanoids is not involved in testosterone-induced coronary relaxation in vitro.

Barium chloride, a nonspecific inhibitor of potassium channels (25), did attenuate the relaxing response to testosterone in rabbit coronary arteries, suggesting that alterations of potassium conductance may be involved partially in the mechanism of relaxation.

In vascular smooth muscle cells, the membrane potential is mainly controlled by $\mathrm{K}+$ flux through sarcolemmal $\mathrm{K}$ channels, and the amount of $\mathrm{K}+$ flux depends on both the number of $\mathrm{K}+$ channels and the electrochemical gradient of potassium across the membrane ${ }^{\text {(26) }}$.

Testosterone-induced relaxation response requires suitable potassium gradients for $\mathrm{K}+$ efflux, and suggests the activation of $\mathrm{K}+$ channels by testosterone ${ }^{(27)}$. Previous studies reported that barium chloride, a non selective blocker of $\mathrm{K}+$ channel profoundly reduces testosterone -induced relaxation responses ${ }^{(8)}$. These findings are consistent with those of the present study, and further suggest the testosterone -induced activation of $\mathrm{K}+$ channels.

In the rabbit coronary artery it has been reported that $\mathrm{K}+$ flux through $\mathrm{K}+$ channels is responsible for determining resting membrane potential, and that the inhibition of $\mathrm{K}+$ channels by some agents induces the contraction of rabbit coronary arteries 
Al-Zendah, M. M. \& Al-Faqeh, A.

${ }^{(28)}$. These reports suggest the importance of $\mathrm{K}+$ channels in the regulation of vascular tone in the rabbit coronary artery under either stimulated or un-stimulated conditions.

Increased $\mathrm{K}$ conductance leading to hyperpolarization of VSM and endothelial cells, has been proposed as the mechanism underlying the acute inhibition of vascular contraction by estrogen (29). Endothelial hyperpolarization increases the release of $\mathrm{NO}^{(30)}$, whereas VSM hyperpolarization decreases voltage-operated $\mathrm{Ca}++$ channel function, inhibits intracellular $\mathrm{Ca}++$ release and lowers the ability of $\mathrm{Ca}++$ to activate contractile proteins ${ }^{(31)}$.

Won et al., ${ }^{(32)}$ states that the relaxation response to testosterone was significantly reduced by 4-aminopyridine, a sensitive blocker of voltage dependent $\mathrm{K}+$ channels, but not by low doses of tetraethyl-ammonium or iberiotoxin, a $\mathrm{Ca} 2+$ activated $\mathrm{K}+$ channel blocker. Testosterone simultaneously reduced the intracellular $\mathrm{Ca} 2+$ concentration $([\mathrm{Ca} 2+] \mathrm{i})$ and tension, and 4-AP effectively antagonized the testosterone-induced change of $[\mathrm{Ca} 2+] \mathrm{i}$ and tension.

Although testosterone-induced coronary vasodilatation appears to be a favorable effect, the literature reveals numerous deleterious cardiovascular associations of androgenic steroid use and of steroid abuse, including reducing serum HDL and HDL/LDL ratios ${ }^{(33)}$, thromboxane- induced vasoconstriction in guinea pigs ${ }^{(34)}$ and monkeys (35) and increasing thromboxane excretion and thromboxane receptors in cultured rat aortic cells ${ }^{(36)}$.

In conclusion, androgens in general and testosterone in particular may have some protective effects on the cardiovascular system through their direct effects upon human vasculature. 


\section{REFERENCES}

1-The Coronary Drug Project Research Group (1973): The coronary drug project. Findings leading to discontinuation of the 25-mg day estrogen group. JAMA 226:652-657.

2-Chute CG, Baron JA, Plymate SR, Kiel DP, Pavia AT, Lozner EC, O'Keefe Tand MacDonald (1987): Sex hormones and coronary artery disease. Am J Med 83:853-859.

3-Sewdarsen M, Jialal I, Vythilingum S,and Desai R (1986): Sex hormone levels in young Indian patients with myocardial infarction. Arterioscelerosis 6: 418-421.

4- Phillps GB, Pinkernell BH, and Jing TY (1994): The association of hypotestosteronemia with coronary artery disease in men.Arterioscler Thromb 14:701-706.

5- Khaw KT, and Barrett-Conner E (1988): Blood pressure and endogenous testosterone in men: an inverse relationship. J Hypertens 6:329-332.

6- Rosano GM, Cornoldi A, Fini M.(2005): Effects of androgens on the cardiovascular system. J Endocrinol Invest. ; 28 (3 Suppl):32-8. 8 Links

7- He H, Yang F, Liu X, Zeng X, Hu Q, Zhu Q, Tu B. (2007) Sex hormone ratio changes in men and postmenopausal women with coronary artery disease. Menopause. May-Jun; 14(3 Pt 1):342-4.

8- Yue P, Chatterjee K, Beale C, Poole-Wilson PA and Collins P. (1995): Testosterone relaxes rabbit coronary arteries and aorta. Circulation 91: 1154-1160.

9- Costarella CE, Stallone JN, Rutecki GW, and Whittier FC.( 1996): Testosterone causes direct relaxation of rat thoracic aorta. J Pharmacol Exp Ther ,; 277: 34-39.

10- Chou, TM, Sudhir K, Hutchison SJ, Ko E, Amidon TM, Collinis $P$ and Chatterjee K. (1996): Testosterone induces dilation of canine coronary conductance and resistance arteries in vivo. Circulation; 94:2614-2619.

11- Ponikowska B, Jankowska EA, Maj J, WegrzynowskaTeodorczyk K, Biel B, Reczuch K, Borodulin-Nadzieja L, Banasiak W, Ponikowski P.(2009): Gonadal and adrenal 
Al-Zendah, M. M. \& Al-Faqeh, A.

androgen deficiencies as independent predictors of increased cardiovascular mortality in men with type II diabetes mellitus and stable coronary artery disease. Int J Cardiol.

12- Wynne FL, Khalil RA. (2003): Testosterone and coronary vascular tone:implications in coronary artery. $\mathrm{J}$ Endocrinol Invest; 26 (2):181-6.

13- Callies F, Strömer H, Schwinger RH, Bölck B, Hu K, Frantz S, Leupold A, Beer S, Allolio B, Bonz AW.(2003) Administration of testosterone is associated with a reduced susceptibility to myocardial ischemia. Endocrinol. Oct; 144(10):4478-83.

14- Jones RD, Hugh Jones T, Channer KS.(2004)The influence of testosterone upon vascular reactivity. Eur J Endocrinol. Jul; 151(1):29-37.

15- Cornoldi A, Caminiti G, Marazzi G, Vitale C, Patrizi R, Volterrani M, Miceli M, Fini M, Spera G, Rosano G.(2009): Effects of chronic testosterone administration on myocardial ischemia, lipid metabolism and insulin resistance in elderly male diabetic patients with coronary artery disease.1: Int J Cardiol.

16- Tsang S, Liu J, Wong TM.(2007): Testosterone and cardioprotection against myocardial ischemia. Cardiovasc Hematol Disord Drug Targets. 2007 Jun; 7(2):119-25.

17- Fallah N, Mohammad K, Nourijelyani K, Eshraghian MR, Seyyedsalehi SA, Raiessi M, Rahmani M, Goodarzi HR, Darvish S, Zeraati H, Davoodi G, Sadeghian S.(2009): Nonlinear association between serum testosterone levels and coronary artery disease in Iranian men. Eur J Epidemiol. Apr 9.

18- van Staa TP, Sprafka JM.(2009)Study of adverse outcomes in women using testosterone therapy. Maturitas. Jan 20; 62(1):7680 .

19- Orshal JM, Khalil RA., (2004): Gender, sex hormones, and vascular tone. Am J Physiol Regul Integr Comp Physiol.; 286(2):R233-

8. 20- Molinari C, Battaglia A, Grossini E, Mary A.S.G., Vassanelli and Vacca G. (2002): The effect of testosterone on 
regional blood flow in prepubertal anaesthetized pigs. J Physiol, 543(1) 365-372.

21- Jones RD, English KM, Jones TH, Channer KS.( 2004): Testosterone- induced coronary vasodilatation occurs via a nongenomic mechanism: evidence of a direct calcium antagonism action. Clin Sci,Mar 1.

22- Deenadayalu VP, White RE, Stallone JN, Gao X, Garcia AJ. (2001): Testosterone relaxes coronary arteries by opening the large- conductance and calcium-activated potassium channel. Am J Physiol; 281: H 1720-7.

23- Ferreira SH, Moncada S, Vane JR. (1971): Indomethacin and aspirin abolish prostaglandin release from the spleen. Nature; 231:237-239.

24- Jiang C, Sarrel PM, Lindsay DC, Poole-Wilson PA, Collins P. (1991): Endothelium-independent relaxation of rabbit coronary artery by $17 \mathrm{~B}$-oestradiol in vitro. Br J Pharmacol. 104:1033-1037.

25- Quayle JM, Standen NB, Stanfield PR. (1988): The voltagedependent block of ATP-sensitive potassium channels of frog skeletal muscle by caesium and barium ions. J Physiol.; 405; 677-697.

26- Yuan XJ. (1995): Voltage-gated $\mathrm{K}+$ currents regulate resting membrane potential and $(\mathrm{Ca}++)$ in pulmonary arterial myocytes. Circ Res; 77:370-378.

27- Won E, Won J, Kwon S, Lee Y, Nam T and Ahn D. (2003): Testosterone causes simultaneous decrease of $\mathrm{Ca}++$ and tension in rabbit coronary arteries: by opening voltage dependent potassium channels. Yonsei Med J.; 44; (6):1027-1033.

28- Yeon DS, Kwon SC, Nam TS, Ahn DS. (2001): Lysophosphatidylcholine decreases delayed rectifier $\mathrm{K}+$ current in rabbit coronary smooth muscle cells. J Vet Med Sci; 63:395-399.

29- Harder D.R and Coulson, P.B (1979): Estrogen receptors and effects of estrogen on membrane electrical properties of coronary vascular smooth muscle. J. Cell. Physiol.; 100: 375-382.

30- Chang, J.K, Moore,P; Fineman,J.R; Soifer, S.J and Heymann.M.A (1992): $\mathrm{K}^{+}$channel pulmonary vasodilation in 
Al-Zendah, M. M. \& Al-Faqeh, A.

fetal lambs: Role of endothelium-derived nitric oxide. J App. Physiol.; 73:188-194.

31- Quast ,U., Guillon, J.M and Cavero, L (1994): Cellular pharmacology of potassium channel openers in vascular smooth muscle. Cardiovasc. Res.; 28:805-810.

32- Won E, Won J, Kwon S, Lee Y, Nam T, Ahn D.(2003): Testosterone causes simultaneous decrease of $[\mathrm{Ca} 2+] \mathrm{I}$ and tension in rabbit coronary arteries: by opening voltage dependent potassium channels. : Yonsei Med J.; 44(6):1027-33.

33- Bagatell CJ, Knopp RH, Vale WW, River JE, Bremner WJ. (1992): Physiologic testosterone levels in normal men suppress high-density lipoprptein cholesterol levels. Ann Intern Med.; 116:967-973.

34- Schror K, Morinelli TA, Masuda A, Matsuda K, Mathur RS, Halushka PV. (1994): Testosterone treatment enhances thromboxane $\mathrm{A}_{2}$ mimetic induced coronary artery vasoconstriction in guinea pigs. Eur. J Clin Invest.; 24(suppl 1):50-52.

35- Weyrich AS, Rejeski WJ, Brubaker PH, Parks JS. (1992): The effects of testosterone on lipids and eicosanoids in cynomolgus monkeys. Med Sci Sports Exerc. 24:333-338. 